\title{
Cultures of human tracheal gland cells of mucous or serous phenotype
}

\author{
Walter E. Finkbeiner • Lorna T. Zlock • Irum Mehdi • \\ Jonathan H. Widdicombe
}

Received: 2 September 2009 / Accepted: 20 October 2009 /Published online: 9 December 2009 / Editor: J. Denry Sato

(C) The Author(s) 2009. This article is published with open access at Springerlink.com

\begin{abstract}
There are two main epithelial cell types in the secretory tubules of mammalian glands: serous and mucous. The former is believed to secrete predominantly water and antimicrobials, the latter mucins. Primary cultures of human airway gland epithelium have been available for almost $20 \mathrm{yr}$, but they are poorly differentiated and lack clear features of either serous or mucous cells. In this study, by varying growth supports and media, we have produced cultures from human airway glands that in terms of their ultrastructure and secretory products resemble either mucous or serous cells. Of four types of porous-bottomed insert tested, polycarbonate filters (Transwells) most strongly promoted the mucous phenotype. Coupled with the addition of epidermal growth factor (EGF), this growth support produced "mucous" cells that contained the large electron-lucent granules characteristic of native mucous cells, but lacked the small electron-dense granules characteristic of serous cells. Furthermore, they showed high levels of mucin secretion and low levels of release of lactoferrin and lysozyme (markers of native serous cells). By contrast, growth on polyethylene terephthalate filters (Cyclopore) in medium lacking EGF produced "serous" cells in which small electron-dense granules replaced the electron-lucent ones, and the cells had high levels of lactoferrin and lysozyme but low levels of mucins.
\end{abstract}

\footnotetext{
W. E. Finkbeiner $\cdot$ L. T. Zlock $\cdot$ I. Mehdi

Department of Pathology, University of California,

San Francisco, CA, USA

\section{J. H. Widdicombe $(\triangle)$}

Department of Physiology \& Membrane Biology,

University of California-Davis,

Davis, CA 95616-8664, USA

e-mail: jhwiddicombe@ucdavis.edu
}

Measurements of transepithelial resistance and shortcircuit current showed that both "serous" and "mucous" cell cultures possessed tight junctions, had become polarized, and were actively secreting $\mathrm{Cl}$.

Keywords Airway mucous gland · Serous cell . Mucous cell $\cdot$ Chloride secretion

\section{Introduction}

Serous and mucous cells are the two predominant epithelial cell types of mammalian airway glands. Their structures and putative functions are very different. Serous cells contain small electron-dense granules, secrete a wide array of antimicrobials, and are believed to be important in the secretion of water (Meyrick and Reid 1970; Basbaum et al. 1990). Mucous cells are packed with large electron-opaque granules containing mucins. They lack most of the antimicrobials of serous cells (Bowes and Corrin 1977; Bowes et al. 1981; Basbaum et al. 1990); their role in the production of the aqueous component of gland secretions is uncertain.

In 1990, Tournier et al. (1990) grew cultures of human tracheal glands in Petri dishes and showed that they secreted lysozyme and bronchial inhibitor, two proteins specific to serous cells of native glands; they did not look for mucous cell markers. In the same year, Sommerhoff and Finkbeiner (1990) also described cultures of human airway gland cells and showed them to possess both mucous and serous cell antigens. These so-called seromucous cells were later grown on permeable supports where they exhibited a transepithelial resistance $\left(R_{\mathrm{te}}\right)$ of $\sim 600 \Omega \mathrm{cm}^{2}$, a transepithelial voltage $\left(V_{\text {te }}\right)$ of $\sim 10 \mathrm{mV}$, and a short-circuit current $\left(I_{\mathrm{sc}}\right.$, an index of active transepithelial ion transport) 
of $\sim 15 \mu \mathrm{A} / \mathrm{cm}^{2}$ (Yamaya et al. 1991). Primary cultures of cat and pig airway glands have also been produced with baseline $I_{\mathrm{sc}}$ s of $\sim 3$ and $\sim 4 \mu \mathrm{A} / \mathrm{cm}^{2}$, respectively (Culp et al. 1992; Chan et al. 1996). All the above values are much less than the $I_{\mathrm{sc}}$ of the surface epithelium of native human airways of $\sim 50 \mu \mathrm{A} / \mathrm{cm}^{2}$ (Knowles et al. 1984; Yamaya et al. 1992), suggesting dedifferentiation of the cultures. This suspicion was confirmed in those studies in which electron microscopy was performed; the cells were lower in height than native gland epithelium and contained few of either the large electron-lucent granules typical of mucous cells or the electron-dense granules typical of serous.

Thus, the adequacy of the initial primary cell cultures as models of either serous or mucous cells is debatable. In 1994, we described culture conditions that produced cells of more markedly mucous phenotype (Finkbeiner et al. 1994). Whereas our earlier seromucous cultures stained both with an antibody specific for native serous cells and an antibody specific for native mucous cells, only the mucous cell antibody stained the new mucous cultures. Furthermore, the mucous cultures contained large electron-opaque granules similar to those of native mucous cells. In this paper, we describe a further set of conditions that produces mucous cells, and more importantly, we describe for the first time cell cultures of obviously serous phenotype.

\section{Materials and Methods}

Human tracheas were obtained, with the consent of the legal next-of-kin, at autopsy. Research protocols were approved by the Institutional Board of the University of California, San Francisco. Acini were isolated by enzymatic dispersion as described (Sommerhoff and Finkbeiner 1990) and plated into $T_{25}$ flasks in DF12 plating medium, which was a 1:1 mixture of Dulbecco's modified Eagle medium and Ham's F12 medium supplemented with fetal calf serum (20\%), penicillin $(100 \mu \mathrm{g} / \mathrm{ml})$, streptomycin $(100 \mathrm{U} / \mathrm{ml})$, gentamicin $(100 \mu \mathrm{g} / \mathrm{ml})$, and amphotericin B $(2.5 \mu \mathrm{g} / \mathrm{ml})$. The day after plating, flasks were rinsed with phosphatebuffered saline (PBS), and the culture medium was switched to BEGM (Lonza; Walkersville, MD). Cells grew out from the attached acini and when approximately $80 \%$ confluent were trypsinized and plated at $3 \times 10^{5}$ cells per square centimeter onto one or other of five different types of inserts: opaque or clear Transwells (\#3401 \& \#3460; Corning Inc., Corning, NY), Millicell HA or CM (Millipore Corp, Billerica, MA), or Cyclopore (Falcon \#353180; BD Biosciences, San Jose, CA). Opaque Transwells are made from polycarbonate, Transwell-Clears and Cyclopores from polyethylene terephthalate (PET), Millicell HA from mixed cellulose esters, and Millicell-CM from hydrophilic polyfluorotetraethylene. All inserts were coated with human placental collagen as described (Coleman et al. 1984). For the first $8-12 \mathrm{~h}$ after seeding, the cultures received plating medium. Following attachment, the cultures were rinsed with PBS, and basic gland serum-free medium (GSFM) was added to the basal side of the insert only. GSFM consisted of 1:1 mixture of Dulbecco's modified Eagle medium and Ham's F12 medium supplemented with insulin $(5 \mu \mathrm{g} / \mathrm{ml})$, transferrin $(5 \mu \mathrm{g} / \mathrm{ml})$, hydrocortisone $(0.5 \mu \mathrm{g} / \mathrm{ml})$ triidothyronine $(20 \mathrm{ng} / \mathrm{ml})$, retinoic acid $\left(5 \times 10^{-8} \mathrm{M}\right)$, bovine serum albumin $(2 \mathrm{mg} / \mathrm{ml})$, and $0.1 \%$ Ultroser $\mathrm{G}$ serum substitute (Pall Biosepra, Cergy, France). GSFM was made up either with or without epidermal growth factor $(25 \mathrm{ng} / \mathrm{ml})$. The sources of our media additives are given elsewhere (Sachs et al. 2003). Medium was changed every 1-2 d. Transepithelial electrical resistance and voltage $\left(V_{\mathrm{te}}\right)$ were checked every $2 \mathrm{~d}$ with a "chopstick" voltmeter (Millicell-ERS; Millipore Corp). When $R_{\mathrm{te}}$ became $\geq 100 \Omega$ $\mathrm{cm}^{2}$, cultures were deemed confluent. This generally occurred within 3 to $5 \mathrm{~d}$ of plating.

For histology and immunocytochemistry, paraffin sections of cell culture inserts and fixed human trachea were prepared. Inserts were fixed for at least $30 \mathrm{~min}$ in buffered formalin $(10 \%)$ and stored in $0.1 \mathrm{M}$ phosphate buffer (pH 7.4). Standard tissue dehydration and paraffin infiltration was performed in a Tissue-Tek VIP processor (Sakura Finetek, Torrance, CA). Sections were cut at $5 \mu \mathrm{m}$ on a rotary microtome and stained with hematoxylin and eosin. For immunohistochemistry, sections were dewaxed and rehydrated in graded alcohol. Endogenous peroxidase activity was quenched by incubating with $3 \%$ hydrogen peroxide in methanol for $10 \mathrm{~min}$. Serum-free protein block (DAKO protein block, reference \#X0909; DAKO, Glostrup, Denmark) was used for $10 \mathrm{~min}$ to reduce background staining. Sections were then incubated with rabbit anti-human lactoferrin (ImmunO, lot $\# 3255 \mathrm{H}$; MP Biomedicals, Solon, $\mathrm{OH}$ ) at $1 / 3,000$ dilution for $30 \mathrm{~min}$ at room temperature. Finally, the secondary antibody (Poly HRP, reference 87-8963; Zymed Laboratories, San Francisco, CA) was added for $10 \mathrm{~min}$. The reaction was revealed with $\mathrm{DAB}$ (DAKO), applied for $5 \mathrm{~min}$, and the slides were counterstained with Mayers hematoxylin, dehydrated in graded alcohol, cleared in xylene, and mounted. For every assay, negative controls using PBS without primary antibody were included. Specimens were viewed and photographed on an Olympus light microscope (Olympus America, Inc., Melville, NY) equipped with a digital imaging system (QImaging, Burnaby, Canada).

For electron microscopy, inserts with attached cells were washed two times with PBS, fixed (60 $\mathrm{min}$, room temperature) with $2.5 \%$ glutaraldehyde in $0.1 \mathrm{M}$ sodium phosphate buffer $(\mathrm{pH} 7.2)$, and post-fixed $\left(1 \mathrm{~h}, 4^{\circ} \mathrm{C}\right)$ in $1 \%$ osmium tetroxide in $0.1 \mathrm{M}$ sodium phosphate buffer (pH 7.2). Next, cells were stained with $1 \%$ uranyl acetate 
in $0.05 \mathrm{M}$ sodium maleate $(\mathrm{pH}$ 5.2), dehydrated, and infiltrated with Polybed 812 (Polysciences, Inc., Warrington, PA). Semi-thin $(0.5 \mu \mathrm{m})$ sections, cut with glass knifes, were stained with toluidine blue for examination with a light microscope. Thin sections of specific areas were then cut with a diamond knife, stained with uranyl acetate and lead citrate, and examined with a JEOL $100 \mathrm{~S}$ electron microscope.

To estimate concentrations of mucin and lysozyme in mucosal liquid, ${ }^{14} \mathrm{C}$-mannitol was added to the basolateral medium. Two days were allowed for this to pass through the tight junctions and equilibrate with the thin film of liquid on the mucosal surface. Control experiments in which cells were exposed to ${ }^{14} \mathrm{C}$-mannitol for varying periods of time showed that equilibration between basolateral and mucosal medium was more than $95 \%$ complete after $\sim 12 \mathrm{~h}$. After $2 \mathrm{~d}$, the mucosal liquid was then obtained by rinsing twice with $300 \mu \mathrm{l}$ PBS. As much as possible of the added PBS was carefully removed with an Eppendorf pipette, and the two $300-\mu l$ samples were pooled. The concentration of mucosal liquid in the pooled rinses (microliter per microliter) was determined by comparing the counts in the pooled rinses with counts in the basolateral medium. The ratio of mucin or lysozyme concentration to the concentration of mucosal liquid gives the concentrations of these proteins in the mucosal liquid.

From 5 to $10 \mathrm{~d}$ after achieving $R_{\mathrm{te}} \geq 100 \Omega \mathrm{cm}^{2}$, filters with attached cell sheets were removed from the bottom of the inserts and studied in conventional Ussing chambers as described (Yamaya et al. 1992). Transepithelial voltage was clamped to zero and the $I_{\mathrm{sc}}$ required recorded continuously. $R_{\mathrm{te}}$ was determined from the current deflections in response to brief voltage pulses across the tissue (Yamaya et al. 1992).

Concentrations of lysozyme and mucin in the samples were determined by established ELISAs (Dubin et al. 2004). For lactoferrin, a new method was used. Microtiter plates (Immulux HB, Dynex, Chantilly, VA) were coated with $100 \mu 1 /$ well rabbit anti-human lactoferrin (MP Biomedicals) at $5 \mu \mathrm{g} / \mathrm{ml}$ in coating buffer $(0.05 \mathrm{M}$ sodium carbonate buffer, $\mathrm{pH}$ 9.6) overnight at $4^{\circ} \mathrm{C}$. Plates were washed with PBS then blocked with $0.25 \mathrm{ml} /$ well of $0.1 \%$ gelatin (Sigma, St. Louis, MO) in PBS for $2 \mathrm{~h}$ at room temperature. After washing with "PBST" (PBS $+0.05 \%$ Tween-20), plates were incubated with varying concentrations of standard (lactoferrin from human milk, Calbiochem, San Diego, CA) or unknown samples, diluted in ELISA buffer (3\% normal goat serum in PBST) for $1 \mathrm{~h}$ at room temperature on a plate shaker (Lab-Line Instruments, Melrose Park, IL). Following PBST washes, peroxidaseconjugated rabbit anti-human lactoferrin antibody (MP Biomedicals) diluted 1:20,000 in ELISA buffer was added and incubated for $1 \mathrm{~h}$ as above. After final washes with
PBST, 2,2'-Azino-bis 3-ethylbenzothiazoline-6-sulfonic acid (ABTS; Sigma) at $1 \mathrm{mg} / \mathrm{ml}$ in phosphate citrate buffer, $\mathrm{pH} 4$.6, with $0.005 \% \mathrm{H}_{2} \mathrm{O}_{2}$ was added for color development. Plates were read at $415 \mathrm{~nm}$ on a Spectramax M2 microplate reader (Molecular Devices, Sunnyvale, CA). Cell protein and DNA were determined with BCA and bisbenzamide, respectively (Cesarone et al. 1979; Smith et al. 1985).

Most pharmacological agents were obtained from Sigma and added as 1:100 or 1:1,000 dilutions of stocks made up in water, ethanol, or DMSO. Addition of vehicle was without effect on any of the properties being measured.

Data are presented as means \pm SE. Student's $t$ test was used to test for statistical differences between means, with $P<0.05$ being considered significant.

\section{Results}

Even after several weeks in culture, cells grown on Millicell-CM filters failed to develop $R_{\mathrm{te}}>100 \Omega \mathrm{cm}^{2}$ as determined with the "chopstick" voltmeter, and in most cases, $R_{\mathrm{te}}$ was below the limit of detection $\left(\sim 25 \Omega \mathrm{cm}^{2}\right)$. In contrast, cells grown on all the other filter types attained $R_{\mathrm{te}}$ s between 100 and $1,000 \Omega \mathrm{cm}^{2}$ within $5 \mathrm{~d}$ of plating.

An initial assessment of phenotype was made from the release of lactoferrin, a specific serous cell marker (Bowes et al. 1981), into the apical medium. However, such measurements were not made on cells grown on Millicell$\mathrm{CM}$ filters because their failure to develop appreciable $R_{\mathrm{te}}$ reflected the absence of tight junctions. There would, therefore, be unrestricted exchange of macromolecules between the apical and basolateral media. For the other culture conditions, Fig. 1 shows that cells on Transwell filters showed considerably lower lactoferrin release than cells grown on other filter types. Furthermore, removing EGF from the culture medium stimulated lactoferrin release from cells on all filter types. For medium lacking EGF, lactoferrin release into the apical medium was not significantly different for cells on Transwell-clear, Cyclopore, or Millicell-HA filters. Across culture conditions, lactoferrin levels in cell lysates paralleled releases into the apical medium (data not shown).

Electron microscopy showed that for the various culture conditions there was a rough correlation between the appearance of lactoferrin in the medium and numbers of electron-dense serous granules resembling those of native serous cells. Such granules were not seen in any cells grown in medium containing EGF, but were present in cells grown in medium lacking EGF provided lactoferrin secretion was $>4 \mathrm{ng} \mathrm{cm}^{-2} \mathrm{~min}^{-1}$ (i.e., in cells grown on Transwell-clear, Cyclopore, and Millicell-HA filters). However, electron-dense granules were most consistently seen 


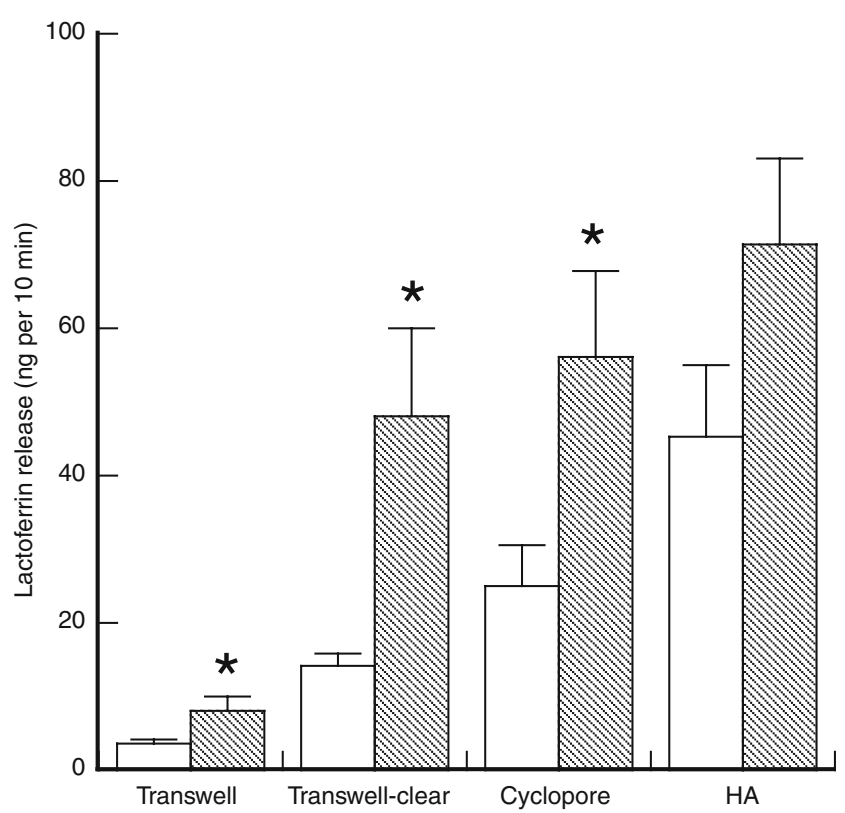

Figure 1. Release of lactoferrin into the mucosal medium. Cells were grown on four types of insert with (open columns) or without (hatched columns) EGF. Removal of EGF increased spontaneous secretion of lactoferrin, though maximal levels were dependent on type of insert. Values are means \pm SE for 8 to 34 inserts from 3 to 11 different cultures. Asterisks indicate values significantly different from those obtained in the presence of EGF.

in cells grown on Cyclopore filters (Fig. 2A). We designate these as "serous cells."

Cells grown on Transwell filters in medium with EGF produced the least lactoferrin. By electron microscopy, these cells were characterized by the presence of large electron-lucent granules resembling mucous granules of native glands (Fig. 2B). We designate these cultures as "mucous cells." Mucous granules were not seen under any of the other culture conditions.

In our earlier studies (Sommerhoff and Finkbeiner 1990; Yamaya et al. 1991), we used cells grown on Millicell-HA inserts in medium supplemented with EGF. Such cells have few secretory granules of any kind (Yamaya et al. 1991; Finkbeiner et al. 1994). We have previously designated them as "seromucous." Table 1 compares mucous, serous, and seromucous cells. Cells grown under the other culture conditions resembled seromucous cells if grown in medium supplemented with EGF or were intermediate between seromucous and serous cells if grown without EGF.

The concentration of mucin in the mucosal liquid over mucus cells was higher than that over serous cells (Table 2). Conversely, the concentration of lysozyme, a specific marker of serous cells (Bowes and Corrin 1977), was higher in the mucosal liquid from serous than mucous cells (Table 2).

Mucous cells had more total protein and DNA than serous cells (Table 3 ). Assuming $4 \mu 1$ of water for every milligram of protein (Widdicombe et al. 1981), then the
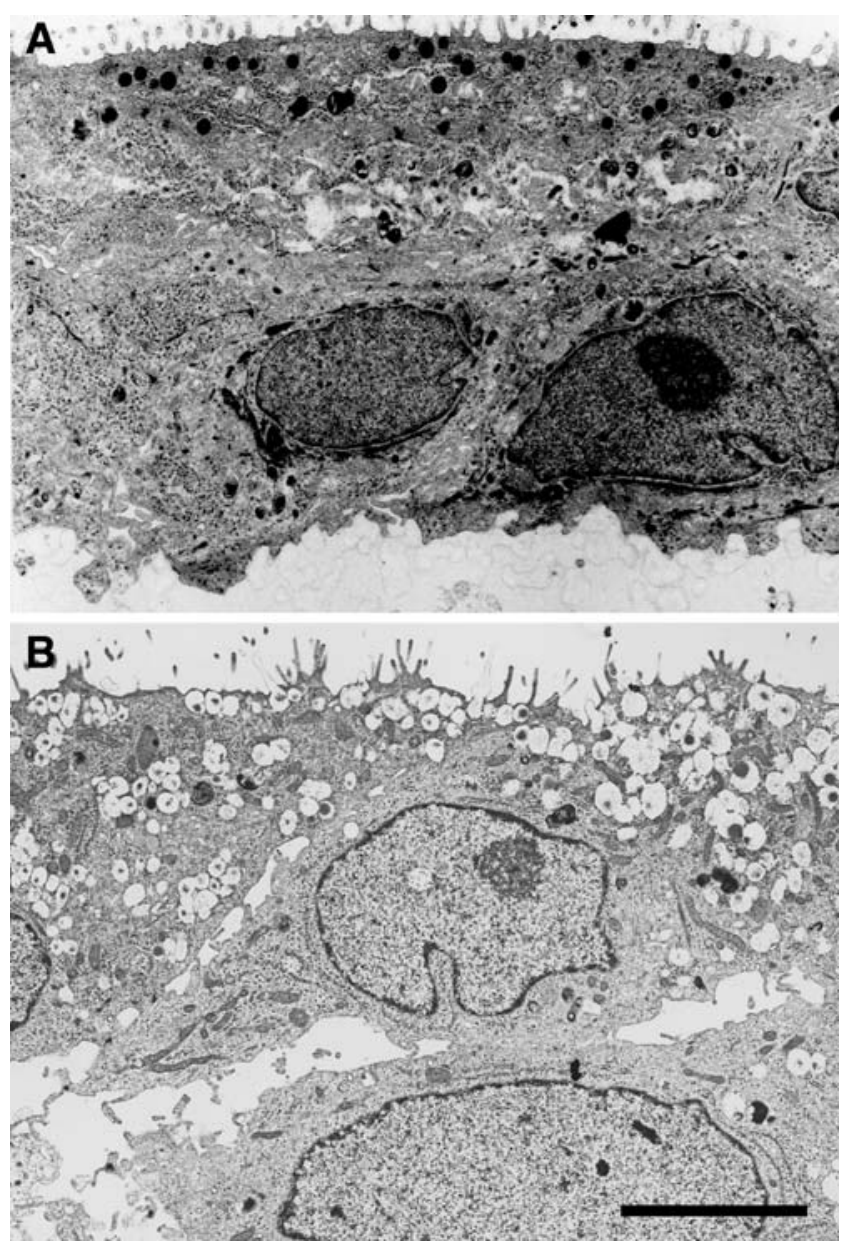

Figure 2. Electron photomicrographs of serous and mucous gland cell cultures. $(A)$ Serous cells. Note the apical electron-dense granules typical of native serous gland cells. $(B)$ Mucous cells. Note the large electron-lucent secretory granules. Scale bar $5 \mu \mathrm{m}$.

serous and mucous cell sheets should be $\sim 10$ and $\sim 25 \mu \mathrm{m}$ thick, respectively. These values are in reasonable agreement with light microscopic cross-sections (Fig. $3 A, B$ ). Consistent with the measurements of lactoferrin release shown in Fig. 1, by immunocytochemistry, the serous cells were positive for lactoferrin (Fig $3 A$ ) and the mucous cells negative (Fig. 3B).

In agreement with our previous results (Finkbeiner et al. 1994; Yamaya et al. 1991), seromucous cultures developed

Table 1. Cell types

\begin{tabular}{llccc}
\hline Cell type & Insert & EGF & $\begin{array}{l}\text { Granules } \\
\text { (lucent/opaque) }\end{array}$ & $\begin{array}{l}\text { Lactoferrin } \\
\text { release } \\
\left(\mathrm{ng} \mathrm{cm}^{-2} \mathrm{~min}^{-1}\right)\end{array}$ \\
\hline Mucous & Transwell & + & $++/ 0$ & 1 \\
Seromucous & Millicell HA & + & $0 / 0$ & 4 \\
Serous & Cyclopore & - & $0 /++$ & 43 \\
\hline
\end{tabular}


Table 2. Composition of mucosal liquid

\begin{tabular}{lcc}
\hline & Serous & Mucous \\
\hline Mucin $(\mu \mathrm{g} / \mathrm{ml})$ & $185 \pm 62$ & $474 \pm 38$ \\
Lysozyme $(\mu \mathrm{g} / \mathrm{ml})$ & $34 \pm 11$ & $12 \pm 4$ \\
\hline
\end{tabular}

Means \pm SE; $n=5$

$R_{\text {te }}$ of $\sim 500 \Omega \mathrm{cm}^{2}$ and $V_{\text {te }}$ of $\sim 10 \mu \mathrm{A} / \mathrm{cm}^{2}$ and showed transient increases in $I_{\mathrm{sc}}$ in response to agents that elevate intracellular Ca. Similar results were obtained on serous and mucous cultures. The former had $R_{\text {te }}$ and $I_{\text {sc }}$ of $263 \pm$ $21 \Omega \mathrm{cm}^{2}$ and $15 \pm 2 \mu \mathrm{A} / \mathrm{cm}^{2}(n=8)$, the latter of $368 \pm$ $48 \Omega \mathrm{cm}^{2}$ and $35 \pm 5 \mu \mathrm{A} / \mathrm{cm}^{2}(n=6)$. Amiloride (a blocker of active $\mathrm{Na}^{+}$absorption) reduced $I_{\mathrm{sc}}$ by $\sim 5 \%$. In the presence of amiloride, $I_{\mathrm{sc}}$ reflects predominantly secretion of $\mathrm{Cl}$, the process that drives gland fluid secretion. Furthermore, most of this $\mathrm{Cl}$ secretion is probably mediated by the cystic fibrosis transmembrane conductance regulator (CFTR), an apical membrane Cl channel (Inglis et al. 1997; Trout et al. 1998). Cholinergic stimulation is the most potent physiological inducer of gland secretion (Finkbeiner and Widdicombe 1992), and we found that methacholine increased amilorideinsensitive $I_{\mathrm{sc}}$ across both serous and mucous cultures (Fig. 4), as it does across seromucous (Yamaya et al. 1991). Added at the end of the experiment, CFTR $_{\text {inh-172, a }}$ specific blocker of CFTR (Ma et al. 2002), abolished the majority of the $I_{\text {sc }}$ (Fig. 4).

\section{Discussion}

Mucous glands are found in the first ten generations of human airways. They decline in numbers and volume with successive generations (Whimster 1986), but it is likely that in the earliest generations, the mucous glands provide most of the mucous blanket that lines the airway lumen. In human trachea and main stem bronchi, for instance, the volume of mucus in the glands has been estimated as 50 times that in the goblet cells of the surface epithelium (Reid 1960).

Glands also play a key role in determining the volume of the airway surface liquid (ASL) that lines the airway lumen. Thus, there is about one gland per square millimeter of airway surface (Tos 1966; Choi et al. 2000). With maximal secretory rates of $\sim 20 \mathrm{nl}$ per gland per minute (Ueki et al. 1980; Choi

Table 3. Protein and DNA contents of mucous vs. serous cell cultures

\begin{tabular}{lcc}
\hline & Serous & Mucous \\
\hline Protein $\left(\mu \mathrm{g} / \mathrm{cm}^{2}\right)$ & $185 \pm 31$ & $469 \pm 28$ \\
DNA $\left(\mu \mathrm{g} / \mathrm{cm}^{2}\right)$ & $17 \pm 2$ & $31 \pm 1$ \\
\hline
\end{tabular}

Means $\pm \mathrm{SE} ; n=5-10$ from two tracheas

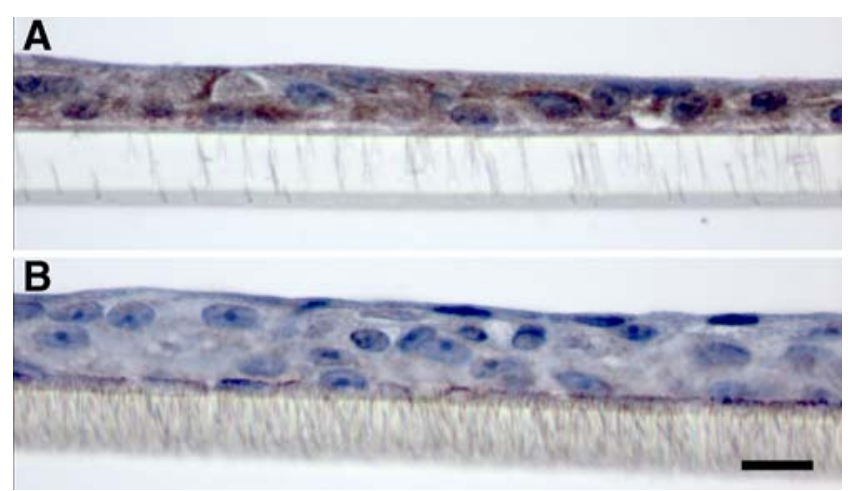

Figure 3. Immunocytochemical localization of lactoferrin in serous $(A)$ or mucous cells $(B)$. The signal (brown deposit) in mucous cells is no greater than in cells that did not receive primary antibody. Scale bar $10 \mu \mathrm{m}$.

et al. 2007), this means that they can add liquid to the airway lumen at up to $120 \mu \mathrm{cm}^{-2} \mathrm{~h}^{-1}$. Given that the depth of ASL is $\sim 10 \mu \mathrm{m}$ in health (Widdicombe and Widdicombe 1995), maximal gland secretion will double the depth of ASL every $30 \mathrm{~s}$. Absorption by the surface epithelium is $\sim 5 \mu \mathrm{cm}^{-2} \mathrm{~h}^{-1}$ (Jiang et al. 1993) and therefore has much slower actions on ASL depth (Wu et al. 1998).

Dysfunction of airway glands has been implicated in several airway diseases. They are, for instance, hypertrophied in asthma, bronchitis, emphysema, and cystic fibrosis, all diseases that are associated with excess airway mucous secretions (Finkbeiner 1999). In cystic fibrosis, glands fail to secrete in response to elevation of intracellular cAMP (Joo et al. 2002; Choi et al. 2007), and it has been suggested that this may lead to a deficiency in gland-derived antimicrobials in ASL, thereby promoting the bacterial colonization characteristic of this disease (Choi et al. 2007).

Thus, there is abundant evidence that mucous glands are important in airway pathophysiology. However, though highly differentiated cultures of surface epithelia from human airways have been available for at least $20 \mathrm{yr}$ (Yankaskas et al. 1985; Wu et al. 1990; Yamaya et al.

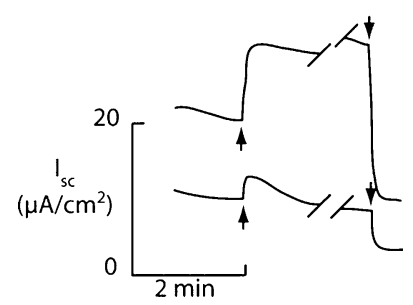

Figure 4. Short-circuit current records from mucous (upper trace) or serous cell cultures (lower trace) derived from the same trachea. Upward-pointing arrows methacholine $\left(10^{-5} \mathrm{M}\right.$, serosal side).

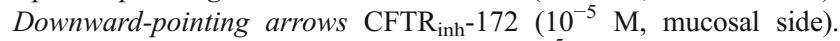
Cells had been pretreated with amiloride $\left(10^{-5} \mathrm{M}\right.$, mucosal side). The gap in the records was for 2 min, during which time ATP $\left(10^{-5} \mathrm{M}\right)$ was added. It caused small transient increases in $I_{\mathrm{sc}} \sim 25 \%$ as large as the methacholine response. 
1992), it has proven harder to obtain cultures of airway gland epithelium that show high levels of differentiation. Though we have earlier reported a technique for obtaining cultures of mucous phenotype (Finkbeiner et al. 1994), most gland cultures are dedifferentiated and bear little resemblance to either the mucous or serous cells of native epithelium (Sommerhoff and Finkbeiner 1990; Tournier et al. 1990; Yamaya et al. 1991; Culp et al. 1992; Chan et al. 1996). By changing the culture conditions, we now have developed cultures that more closely resemble either serous or mucous cells. Our mucous cultures contain electronlucent granules typical of mucous cells in general; they have no electron-dense granules. They release relatively low levels of lactoferrin and have relatively low levels of lysozyme in their mucosal liquid; lactoferrin and lysozyme localize exclusively to serous cells of native epithelium (Bowes and Corrin 1977; Bowes et al. 1981). They are negative for lactoferrin by immunocytochemistry. In contrast, our "serous" cultures contain electron-dense but not electron-lucent granules. They release 40 times as much lactoferrin as the mucous cultures and have high levels of lysozyme, but low levels of mucus, in their mucosal medium. They are positive for lactoferrin by immunocytochemistry.

Epithelia act as barriers, and the formation of tight junctions between the cells is key to this function. The development of tight junctions is associated with the attainment of a transepithelial resistance $\left(R_{\mathrm{te}}\right)$ that can vary anywhere from $\sim 5$ to $\sim 5,000 \Omega \mathrm{cm}^{2}$ depending on the epithelium (Fromter and Diamond 1972). When tight junctions are opened, by say removal of extracellular $\mathrm{Ca}^{2+}, R_{\mathrm{te}}$ drops to essentially zero (Cereijido et al. 1989), certainly to less than $5 \Omega \mathrm{cm}^{2}$. Thus, the $R_{\mathrm{te}} \mathrm{s}$ of $263 \pm$ $21 \Omega \mathrm{cm}^{2}$ for serous cells and $368 \pm 48 \Omega \mathrm{cm}^{2}$ for mucous cells show that tight junctions have formed and indicate that these epithelia are of intermediate "tightness." Resistances of airway surface epithelia are generally in the range of 100 to $1,000 \Omega \mathrm{cm}^{2}$ (Finkbeiner and Widdicombe 1992).

A second major function of epithelia is the vectorial transport of ions, which in leaky epithelia drives transepithelial osmotic water flows (Diamond 1979). In secretory epithelia of mammals, the major vectorial transepithelial transport is active secretion of $\mathrm{Cl}$. This, and other electrogenic ion transport processes operating across the epithelium, can be measured in Ussing chambers as short-circuit current ( $I_{\mathrm{sc}}$; Ussing and Zerahn 1951). Thus, $I_{\mathrm{sc}}$ is a rough index of differentiation of cell cultures; as differentiation and cell height of cultures increases, so too do both the total extent of cell membrane and the $I_{\mathrm{sc}}$. For instance, our first cultures of human tracheal epithelium were squamous, about $2 \mu \mathrm{m}$ in cell height and had $I_{\mathrm{sc}} \mathrm{S}$ of $\sim 3 \mu \mathrm{A} / \mathrm{cm}^{2}$ (Widdicombe et al. 1985). When we obtained cultures of full mucociliary differentiation, of $\sim 50-\mu \mathrm{m}$ height, they displayed $I_{\mathrm{sc}} \mathrm{s}$ of $\sim 50 \mu \mathrm{A} / \mathrm{cm}^{2}$, the same as native epithelium (Yamaya et al. 1992). We obtained exactly similar results with dog (Coleman et al. 1984; Kondo et al. 1991) and bovine tracheal epithelium (Kondo et al. 1993). The values reported here of $15 \mu \mathrm{A} / \mathrm{cm}^{2}$ for serous cultures and $35 \mu \mathrm{A} / \mathrm{cm}^{2}$ for mucous are therefore quite respectable and indicative of high levels of differentiation. We suspect that the higher value in mucous than serous cells reflects the higher protein content (and therefore cell height) of the former. Amiloride, the inhibitor of active $\mathrm{Na}^{+}$absorption, had little effect on $I_{\mathrm{sc}}$, suggesting that secretion of $\mathrm{Cl}$ was the predominant active transepithelial ion transport process, a conclusion supported by the inhibitory action of CFTR $_{\text {inh }}-172$, a blocker of CFTR, the major $\mathrm{Cl}$ channel in the apical membrane of mammalian epithelia (Fuller and Benos 1992).

We had earlier obtained mucous cultures by growth on calfskin collagen gels fixed with glutaraldehyde (Finkbeiner et al. 1994). The cells had mucous granules, but their $I_{\mathrm{sc}}$ was only $\sim 2.5 \mu \mathrm{A} / \mathrm{cm}^{2}$. Thus, the mucous cultures described here are grown on simpler supports and are much better differentiated in terms of their $I_{\mathrm{sc}}$.

In conclusion, we here describe a set of simple techniques needed to produce cultures of human tracheal glands of either mucous or serous phenotype. These cultures resemble native serous or mucous cells in their ultrastructure, secretory processes, and immunocytochemistry. They generate appreciable values of $R_{\mathrm{te}}$ demonstrating that they possess tight junctions and form effective barriers to ion permeation. Finally, Ussing chamber data indicate that as expected for gland cells they possess high levels of active transepithelial $\mathrm{Cl}$ secretion. These cells should prove useful in studies of airway gland function in health and disease.

Acknowledgments This study was supported by DK75217, a Research Development Program grant from the Cystic Fibrosis Foundation, Cystic Fibrosis Research Inc., and a gift from Pam Fair and Glen Sullivan.

Open Access This article is distributed under the terms of the Creative Commons Attribution Noncommercial License which permits any noncommercial use, distribution, and reproduction in any medium, provided the original author(s) and source are credited.

\section{References}

Basbaum C. B.; Jany B.; Finkbeiner W. E. The serous cell. Annu. Rev. Physiol. 52: 97-113; 1990.

Bowes D.; Clark A. E.; Corrin B. Ultrastructural localisation of lactoferrin and glycoprotein in human bronchial glands. Thorax 36: 108-115; 1981.

Bowes D.; Corrin B. Ultrastructural immunocytochemical localisation of lysozyme in human bronchial glands. Thorax 32: 163-170; 1977.

Cereijido M.; Gonzalez-Mariscal L.; Contreras G. Tight junction: barrier between higher organisms and environment. NIPS 4: 7276; 1989. 
Cesarone C. F.; Bolognesi C.; Santi L. Improved microfluorometric DNA determination in biological material using Hoechst 33258. Anal. Biochem. 100: 188-197; 1979.

Chan M. H.; Dwyer T. M.; Farley J. M. Cocaine inhibits chloride secretion by swine tracheal submucosal gland cells grown in culture. Toxicol. Appl. Pharmacol. 139: 387-393; 1996.

Choi H. K.; Finkbeiner W. E.; Widdicombe J. H. A comparative study of mammalian tracheal mucous glands. J. Anat. 197: 361-372; 2000.

Choi J. Y.; Joo N. S.; Krouse M. E.; Wu J. V.; Robbins R. C.; Ianowski J. P.; Hanrahan J. W.; Wine J. J. Synergistic airway gland mucus secretion in response to vasoactive intestinal peptide and carbachol is lost in cystic fibrosis. J. Clin. Invest. 117: 31183127; 2007.

Coleman D. L.; Tuet I. K.; Widdicombe J. H. Electrical properties of dog tracheal epithelial cells grown in monolayer culture. Am. J. Physiol. 246: C355-C359; 1984.

Culp D. J.; Lee D. K. P.; Penney D. P.; Marin M. G. Cat tracheal gland cells in primary culture. Am. J. Physiol. 263: L264-L275; 1992.

Diamond J. M. Osmotic water flow in leaky epithelia. J. Membr. Biol. 51: 195-216; 1979.

Dubin R. F.; Robinson S. K.; Widdicombe J. H. Secretion of lactoferrin and lysozyme by cultures of human airway epithelium. Am. J. Physiol. 286: L750-L755; 2004.

Finkbeiner W. E. Physiology and pathology of tracheobronchial glands. Respir. Physiol. 118: 77-83; 1999.

Finkbeiner W. E.; Widdicombe J. H. Control of nasal airway secretions, ion transport, and water movement. In: Parent R. A. (ed) Treatise on Pulmonary Toxicology. Volume 1. Comparative Biology of the Normal Lung. CRC Press, Boca Raton, FL, pp 633-657; 1992.

Finkbeiner W. E.; Shen B. Q.; Widdicombe J. H. Chloride secretion and function of serous and mucous cells of human airway glands. Am. J. Physiol. 267: L206-L210; 1994.

Fromter E.; Diamond J. Route of passive ion permeation in epithelia. Nat. New Biology 235: 9-13; 1972.

Fuller C. M.; Benos D. J. CFTR! Am. J. Physiol. 263: C267-C286; 1992.

Inglis S. K.; Corboz M. R.; Taylor A. E.; Ballard S. T. Effects of anion transport inhibition on mucus secretion by airway submucosal glands. Am. J. Physiol. 272: L372-L377; 1997.

Jiang C.; Finkbeiner W. E.; Widdicombe J. H.; McCray Jr. P. B.; Miller S. S. Altered fluid transport across airway epithelium in cystic fibrosis. Science 262: 424-427; 1993.

Joo N. S.; Irokawa T.; Wu J. V.; Robbins R. C.; Whyte R. I.; Wine J. J. Absent secretion to vasoactive intestinal peptide in cystic fibrosis airway glands. J. Biol. Chem. 277: 50710-50715; 2002.

Knowles M. R.; Murray G. F.; Shallal J. A.; Askin F.; Ranga V.; Gatzy J. T.; Boucher R. C. Bioelectric properties and ion flow across excised human bronchi. J. Appl. Physiol. 56: 868-877; 1984.

Kondo M.; Finkbeiner W. E.; Widdicombe J. H. Simple technique for culture of highly differentiated cells from dog tracheal epithelium. Am. J. Physiol. 261: L106-L117; 1991.

Kondo M.; Finkbeiner W. E.; Widdicombe J. H. Cultures of bovine tracheal epithelium with differentiated ultrastructure and ion transport. In Vitro Cell. Dev. Biol. 29A: 19-24; 1993.

Ma T.; Thiagarajah J. R.; Yang H.; Sonawane N. D.; Folli C.; Galietta L. J.; Verkman A. S. Thiazolidinone CFTR inhibitor identified by high-throughput screening blocks cholera toxin-induced intestinal fluid secretion. J. Clin. Invest. 110: 1651-1658; 2002.

Meyrick B.; Reid L. Ultrastucture of cells in human bronchial submucosal glands. J. Anat. 107: 291-299; 1970.

Reid L. Measurement of the bronchial mucous gland layer: a diagnostic yardstick in chronic bronchitis. Thorax 15: 132-141; 1960.

Sachs L. A.; Finkbeiner W. E.; Widdicombe J. H. Effects of media on differentiation of cultured human tracheal epithelium. In Vitro 39A: 56-62; 2003.

Smith P. K.; Krohn R. I.; Hermanson G. T.; Mallia A. K.; Gartner F. H.; Provenzano M. D.; Fujimoto E. K.; Goeke N. M.; Olson B. J.; Klenk D. C. Measurement of protein using bicinchoninic acid. Anal. Biochem. 71: 1392-1401; 1985.

Sommerhoff C. P.; Finkbeiner W. E. Human tracheobronchial submucosal gland cells in culture. Am. J. Respir. Cell Mol. Biol. 2: $41-50 ; 1990$.

Tos M. Development of the tracheal glands in man. Acta Pathol. Microbiol. Scand. Suppl. 185: 1-130; 1966.

Tournier J. M.; Merten M.; Meckler Y.; Hinnrasky J.; Fuchey C.; Puchelle E. Culture and characterization of human tracheal gland cells. Am. Rev. Respir. Dis. 141: 1280-1288; 1990.

Trout L.; Gatzy J. T.; Ballard S. T. Acetylcholine-induced liquid secretion by bronchial epithelium: role of $\mathrm{Cl}-$ and $\mathrm{HCO}_{3}$-transport. Am. J. Physiol. 275: L1095-L1099; 1998.

Ueki I.; German V. F.; Nadel J. Micropipette measurement of airway submucosal gland secretion: autonomic effects. Am. Rev. Respir. Dis. 121: 351-357; 1980.

Ussing H. H.; Zerahn K. Active transport of sodium as the source of electric current in short-circuited isolated frog skin. Acta Physiol. Scand. 23: 110-127; 1951.

Whimster W. F. Number and mean volume of individual submucous glands in the human tracheobronchial tree. Appl. Pathol. 4: 24-32; 1986.

Widdicombe J. H.; Basbaum C. B.; Highland E. Ion contents and other properties of isolated cells from dog tracheal epithelium. Am. J. Physiol. 241: C184-C192; 1981.

Widdicombe J. H.; Coleman D. L.; Finkbeiner W. E.; Tuet I. K. Electrical properties of monolayers cultured from cells of human tracheal mucosa. J. Appl. Physiol. 58: 1729-1735; 1985.

Widdicombe J. H.; Widdicombe J. G. Regulation of human airway surface liquid. Respir. Physiol. 99: 3-12; 1995.

Wu D. X.; Lee C. Y.; Uyekubo S. N.; Choi H. K.; Bastacky S. J.; Widdicombe J. H. Regulation of the depth of surface liquid in bovine trachea. Am. J. Physiol. 274: L388-L395; 1998.

Wu R.; Martin W. R.; Robinson C. B.; St. George J. A.; Plopper C. G.; Kurland G.; Last J. A.; Cross C. E.; McDonald R. J.; Boucher R. Expression of mucin synthesis and secretion in human tracheobronchial epithelial cells grown in culture. Am. J. Respir. Cell Mol. Biol. 3: 467-478; 1990.

Yamaya M.; Finkbeiner W. E.; Chun S. Y.; Widdicombe J. H. Differentiated structure and function of cultures from human tracheal epithelium. Am. J. Physiol. 262: L713-L724; 1992.

Yamaya M.; Finkbeiner W. E.; Widdicombe J. H. Ion transport by cultures of human tracheobronchial submucosal glands. Am. J. Physiol. 261: L485-L490; 1991.

Yankaskas J. R.; Cotton C. U.; Knowles M. R.; Gatzy J. T.; Boucher R. C. Culture of human nasal epithelial cells on collagen matrix supports. A comparison of bioelectric properties of normal and cystic fibrosis epithelia. Am. Rev. Respir. Dis. 132: 1281-1287; 1985. 